\title{
O PROCESSO DE ESCOLARIZAÇÃO DO SURDO USUÁRIO DE LIBRAS E SEUS DESAFIOS: REVISÃO DE LITERATURA
}

\author{
THE PROCESS OF SCHOOLING THE DEAF USER OF LIBRAS AND ITS \\ CHALLENGES: LITERATURE REVIEW
}

\author{
Adriana Ribeiro de Freitas* \\ Cláudia Maria Silva Ribeiro Amaral** \\ Neuma Chaveiro ${ }^{* * *}$
}

\section{Resumo}

A política educacional inclusiva objetiva uma educação integradora. Ainda que a Legislação reconheça a Libras como língua oficial dos surdos, essa população encontra dificuldades no processo de escolarização. Assim, este estudo tem como finalidade investigar as principais barreiras enfrentadas pelo surdo no processo de escolarização por meio de uma revisão da literatura, realizada na Biblioteca Virtual em Saúde (BVS) no mês de setembro de 2018. Foram identificadas 19 publicações, categorizadas em quadros nos quais constam autor(es), ano, título, objetivo e conclusão de cada uma das pesquisas encontradas. A ausência de uma comunicação eficaz, as diferenças linguísticas entre a Libras e o português, a falta de adaptação das atividades pedagógicas e o desconhecimento dos impactos da surdez no processo de aquisição da escrita, são apontadas como barreiras para o processo de escolarização do surdo.

Palavras-chave: Surdez e aprendizagem. Surdez e leitura. Surdez e escrita. Escolarização do surdo.

\section{Introdução}

De acordo com o censo demográfico de 2010, mais de 45 milhões de brasileiros, ou seja, 23,9\% da população total, apresenta algum tipo de deficiência, seja ela visual, auditiva, motora, mental ou intelectual. A deficiência auditiva afeta $5,1 \%$ da população brasileira, ocupando o terceiro lugar em ocorrência no país. Dos mais de 45 milhões de pessoas declaradas com deficiência, 7,6\% são totalmente surdas e é esta população que o presente estudo deseja referenciar (BRASIL, 2012).

\footnotetext{
* Doutorado em Ciências da Saúde pela Universidade Federal de Goiás (UFG), Goiânia, Goiás, Brasil. E-mail: driribeiro70@gmail.com

** Graduada em Fonoaudiologia pela Pontifícia Universidade Católica de Goiás (PUC-Goiás), Goiânia, Goiás, Brasil.E-mail: claudia_amaral2109@ hotmail.com

*** Pós-Doutorado pela Universidade de Barcelona (UB), Professora da Universidade Federal de Goiás (UFG), Goiânia, Goiás, Brasil. E-mail: neumachaveiro@ufg.br
} 
Caracterizada como uma redução sensorial, as perdas auditivas têm naturezas diversas - podem ser congênitas, adquiridas ao longo da vida ou consequência natural do envelhecimento. Quando congênita ou adquirida antes da aquisição de uma língua, confere à pessoa características linguísticas diferenciadas pela aquisição de um sistema linguístico próprio, a língua de sinais. Portanto, a diferença entre pessoas surdas e ouvintes não se dá apenas pela ausência da audição, mas por peculiaridades linguísticas (BEHARES, 1993).

Em relação aos limiares auditivos, estes podem ser classificados como: audição normal ( 0 e $25 \mathrm{~dB})$; perda de grau leve (26 e $40 \mathrm{~dB})$; perda de grau moderado (41 e $70 \mathrm{~dB})$; perda de grau severo (71 e $90 \mathrm{~dB}$ ); e perda de grau profundo (> $91 \mathrm{~dB}$ ) (DAVIS; SILVERMANN, 1970).

Seja qual for a natureza ou o grau, a perda auditiva prejudica o desenvolvimento da linguagem oral do surdo, dificulta sua socialização, compromete o processo de aprendizagem escolar e o alcance do sucesso acadêmico. Além disso, as perdas auditivas de grau severo e profundo impactam sobremaneira o desenvolvimento dos aspectos sintático e semântico, tornando o processo de aquisição da leitura e da escrita muito difícil e lento, muitas vezes levando o surdo ao abandono escolar (ALMEIDA; SANTOS, 2003; FERREIRA, 2004).

A década de 1990 foi marcada pela defesa da inclusão educacional. Nesse sentido, políticas nacionais importantes surgiram no Brasil, baseadas na Lei de Diretrizes e Bases da Educação Nacional, promulgada em 1996 (BRASIL, 1996). Em resposta a esse movimento, em 2008, o Ministério da Educação e Cultura (MEC) criou a Política Nacional de Educação Especial na Perspectiva da Educação Inclusiva. A partir de então, todos os estados e municípios foram orientados a receber, em suas instituições de ensino, alunos com necessidades educacionais específicas (BRASIL, 2015).

Após uma longa trajetória de discriminação e imposições oralistas, o surdo teve reconhecidas suas características linguísticas pela Lei $n^{\circ}$ 10.436/2002, que considera a língua de sinais como o meio oficial de comunicação dos surdos e necessária ao seu acesso à informação (CHAVEIRO et al., 2013; PEREIRA; VIEIRA, 2009). Posteriormente, houve sua regulamentação através do Decreto $\mathrm{n}^{\circ} 5.626 / 2005$, que estabeleceu a Libras como a primeira língua do surdo e a língua portuguesa como segunda língua (BRASIL, 2005).

Embora essa Lei seja uma grande conquista para a comunidade surda, sua efetivação ainda deixa a desejar na inclusão escolar dessa população, visto que não foram realizadas, no cotidiano da sala de aula, as modificações pedagógicas e de capacitação de recursos humanos 
necessárias para promover sua inclusão, impedindo a construção do conhecimento almejado por aqueles que a frequentam (BUFFA, 2005).

Ainda que a prerrogativa da política educacional brasileira tenha como objetivo proporcionar uma educação integradora, que beneficie a todos dentro da escola regular, e apesar de a Legislação reconhecer a Libras como língua oficial dos surdos, essa população ainda encontra várias dificuldades em relação ao seu desempenho no processo de escolarização por falta de realização das adaptações necessárias (NUNES et al., 2015).

Com o intuito de ampliar o conhecimento fonoaudiológico sobre o processo de escolarização do surdo usuário de Libras, surgem duas questões: quais são as principais barreiras enfrentadas pelo surdo usuário de Libras na aprendizagem? Quais adaptações pedagógicas potencializam a formação educacional do surdo usuário de Libras?

A proposta deste estudo, portanto, é responder a essas perguntas, analisando a literatura científica com o objetivo de identificar e analisar estudos realizados com alunos surdos usuário de Libras em processo de aprendizagem.

\section{Metodologia}

Trata-se de uma revisão integrativa da literatura, método de análise de estudos em que pesquisas são sintetizadas a fim de inferir um tema específico, com a finalidade de contribuir para o conhecimento do assunto investigado (MENDES et al., 2008).

Foram realizados os seguintes passos: identificação do tema; estabelecimento de critérios de inclusão e exclusão; definição das informações; busca na literatura; categorização dos estudos; avaliação dos estudos incluídos na revisão; interpretação dos resultados e síntese do conhecimento evidenciado nos artigos analisados.

A investigação dos artigos foi realizada no mês de setembro de 2018, na Biblioteca Virtual em Saúde (BVS). Foram pesquisadas as bases de dados da Literatura da América Latina e do Caribe em Ciências da Saúde (Lilacs), Literatura Internacional em Ciências da Saúde (MedLine), Scientific Electronic Library Online (SciELO) e Biblioteca Cochrane. Para a busca dos artigos, foram usadas as seguintes expressões: "surdez e aprendizagem", "surdez e leitura", "surdez e escrita" e "surdez e escolarização".

Os critérios de inclusão definidos para este estudo foram: artigos entre 2008 e 2018, escritos em português, que discutissem o processo de ensino e aprendizagem das pessoas surdas que usam Língua de sinais. 


\section{Resultados}

No primeiro levantamento, foram identificadas 87 publicações, refinadas pela leitura atenta dos títulos, verificando sua adequação às questões norteadoras, tendo sido selecionados 30 artigos. Realizou-se, então, a leitura dos objetivos e resumos, quando foram selecionados 24 artigos. Após a leitura dos artigos, foram selecionadas 19 publicações.

Para a análise e a interpretação dos dezenove artigos científicos selecionados, foram preenchidos três quadros sinópticos. Cada quadro apresentou as seguintes informações: autor, ano de publicação, título do artigo, revista de publicação, objetivos e conclusão dos estudos.

Os dados foram analisados detalhadamente, de forma crítica, buscando compreender resultados, análises e discussões realizados pelos autores sobre os desafios enfrentados no processo de escolarização do surdo usuário de libras.

No Quadro 1 encontra-se a síntese de cinco artigos científicos que pesquisaram sobre os impactos das diferenças linguísticas entre a Libras e o português no processo de aprendizagem do surdo.

O Quadro 2 sintetiza nove artigos científicos que discorreram sobre a importância do uso de metodologias e estratégias pedagógicas adaptadas ao processo de aprendizagem do surdo.

Por fim, no Quadro 3, há uma síntese de cinco artigos que pesquisaram sobre a adaptação do ambiente pedagógico como facilitadora do processo de aprendizagem.

Quadro 1. Estudos referentes ao impacto das diferenças linguísticas entre a Libras e o português no processo de aprendizagem do surdo

\begin{tabular}{|c|c|c|}
\hline Autor/Ano/Título & Objetivos & Conclusão \\
\hline $\begin{array}{l}\text { CRATO, Aline } \\
\text { Nascimento; CARNIO, } \\
\text { Maria Silvia. 2010. } \\
\text { Marcação de tempo por } \\
\text { surdos sinalizadores } \\
\text { brasileiros. }\end{array}$ & $\begin{array}{l}\text { Averiguar se existe relação } \\
\text { entre o desempenho no uso } \\
\text { da flexão verbal de tempo e } \\
\text { grau de escolaridade. } \\
\text { Verificar os marcadores de } \\
\text { tempo utilizados na } \\
\text { produção de frases na } \\
\text { Libras e na Língua } \\
\text { Portuguesa escrita. }\end{array}$ & $\begin{array}{l}\text { Os surdos do estudo utilizam adequadamente } \\
\text { marcadores de tempo na maioria das frases } \\
\text { expressas na Libras, mas apresentam } \\
\text { dificuldade na Língua Portuguesa escrita. }\end{array}$ \\
\hline $\begin{array}{l}\text { ANDRADE, Wagner } \\
\text { Teobaldo Lopes de et al. } \\
\text { 2010. Sobre a coesão do } \\
\text { texto dos surdos aos }\end{array}$ & $\begin{array}{l}\text { Investigar a compreensão, } \\
\text { por ouvintes, do texto } \\
\text { escrito por surdos, em } \\
\text { função da ocorrência de }\end{array}$ & $\begin{array}{l}\text { Verificou-se que os fragmentos referidos } \\
\text { como de conteúdo mais compreendido foram } \\
\text { os produzidos por ouvintes, seguidos dos } \\
\text { com mais de uma marca de oralidade }\end{array}$ \\
\hline
\end{tabular}




\begin{tabular}{|c|c|c|}
\hline $\begin{array}{l}\text { olhos dos ouvintes: o } \\
\text { uso das marcas de } \\
\text { oralidade na escrita. }\end{array}$ & $\begin{array}{l}\text { marcas da oralidade na } \\
\text { escrita. }\end{array}$ & $\begin{array}{l}\text { produzidos por surdos; os menos } \\
\text { compreendidos foram os sem marca de } \\
\text { oralidade produzidos por surdos. O estudo } \\
\text { sugere que as marcas de oralidade } \\
\text { promoveram a coesão textual dos surdos, } \\
\text { facilitando a compreensão do conteúdo da } \\
\text { sua escrita por ouvintes. }\end{array}$ \\
\hline $\begin{array}{l}\text { PEREIRA, Veronica } \\
\text { Aparecida; } \\
\text { ALMEIDA-VERDU, } \\
\text { Ana Cláudia Moreira. } \\
\text { 2012. Avaliação do ler e } \\
\text { do escrever de surdos } \\
\text { pela língua brasileira } \\
\text { de sinais. }\end{array}$ & $\begin{array}{l}\text { Caracterizar o desempenho } \\
\text { do ler e do escrever em } \\
\text { quatro alunos surdos, } \\
\text { usuários de Libras em fase } \\
\text { de alfabetização. }\end{array}$ & $\begin{array}{l}\text { Os dados evidenciam que os alvos de } \\
\text { investimento para a programação de } \\
\text { condições de ensino do ler e do escrever em } \\
\text { aprendizes surdos requerem adequações mais } \\
\text { em relação à modalidade da comunicação do } \\
\text { que em procedimentos de ensino. }\end{array}$ \\
\hline $\begin{array}{l}\text { ALMEIDA, Elizabeth } \\
\text { Oliveira Crepaldi de et } \\
\text { al. 2010. Coesão textual } \\
\text { na escrita de um grupo } \\
\text { de adultos surdos } \\
\text { usuários da língua de } \\
\text { sinais Brasileira. }\end{array}$ & $\begin{array}{l}\text { Investigar a coesão textual } \\
\text { em produções escritas por } \\
\text { quatro adultos surdos } \\
\text { usuários da LIBRAS. } \\
\text { Verificar a possível } \\
\text { interferência da Libras na } \\
\text { escrita em português. }\end{array}$ & $\begin{array}{l}\text { A produção escrita dos surdos apresenta } \\
\text { coesão, porém com interferência da Libras, o } \\
\text { que prejudica a compreensão por parte do } \\
\text { leitor. Quanto menor a coesão textual, maior } \\
\text { a necessidade de explicações do autor sobre } \\
\text { o que quis dizer com texto. }\end{array}$ \\
\hline $\begin{array}{l}\text { NADER, Júlia Maria } \\
\text { Vieira. 2008. A relação } \\
\text { da língua materna com } \\
\text { o ensino/aprendizagem } \\
\text { de crianças surdas } \\
(P A P) \text {. }\end{array}$ & $\begin{array}{l}\text { Compreender em que } \\
\text { medida há } \\
\text { ensino/aprendizagem por } \\
\text { parte de alunos cuja língua } \\
\text { materna (LM) não coincide } \\
\text { com a língua de instrução } \\
\text { da escola e da família. }\end{array}$ & $\begin{array}{l}\text { Ainda que não tenham adquirido uma língua, } \\
\text { os surdos se inserem desde a primeira } \\
\text { infância no mundo da linguagem. Todos os } \\
\text { elementos de estruturação simbólica } \\
\text { proporcionados pela mãe em contato com } \\
\text { filho, sejam eles provindos da língua falada } \\
\text { ou de gestos, expressões faciais e } \\
\text { movimentos corporais que possibilitam a } \\
\text { comunicação na ausência de uma língua } \\
\text { comum entre mães ouvintes e filhos surdos } \\
\text { assumem papel de LM para eles e } \\
\text { possibilitam seu desenvolvimento cognitivo. } \\
\text { Porém, tal linguagem é restrita e os restringe } \\
\text { no momento da aprendizagem dos conteúdos } \\
\text { escolares que lhes são apresentados somente } \\
\text { por meio da língua portuguesa. (AU) }\end{array}$ \\
\hline
\end{tabular}

Fonte: Dados da pesquisa. 
Quadro 2. Estudos referentes à importância do uso de metodologias e estratégias pedagógicas adaptadas para o processo de aprendizagem do surdo. Goiânia, 2018.

\begin{tabular}{|c|c|c|}
\hline Autor/Ano/ Título & Objetivos & Conclusão \\
\hline $\begin{array}{l}\text { WELTER, Gabriela et al. } \\
\text { 2015. Intervençôes e } \\
\text { metodologias empregadas } \\
\text { no ensino da escrita e leitura } \\
\text { de indivíduos surdos: } \\
\text { revisão de literatura. }\end{array}$ & $\begin{array}{l}\text { Verificar, na literatura, } \\
\text { intervenções/metodologias } \\
\text { aplicadas no processo de } \\
\text { aprendizagem da escrita por } \\
\text { indivíduos surdos. }\end{array}$ & $\begin{array}{l}\text { Os estudos têm pensado em } \\
\text { melhorias para o ensino/intervenção } \\
\text { na escrita de sujeitos surdos e a } \\
\text { Fonoaudiologia está se inserindo } \\
\text { nessa área tanto clinicamente como } \\
\text { em pesquisas. }\end{array}$ \\
\hline $\begin{array}{l}\text { NASCIMENTO, Gicélia } \\
\text { Barreto; KESSLER, Themis } \\
\text { Maria. 2015. Efeitos de } \\
\text { oficinas de contar histórias } \\
\text { com livros infantis } \\
\text { realizadas com familiares de } \\
\text { crianças surdas. }\end{array}$ & $\begin{array}{l}\text { Analisar os efeitos } \\
\text { estratégias nas } \\
\text { familiares de crianças surdas } \\
\text { ao contar história por meio de } \\
\text { livros infantis, antes e depois } \\
\text { de oficinas r com } \\
\text { fonoaudiólogo. }\end{array}$ & $\begin{array}{l}\text { Houve mudanças qualitativas na } \\
\text { maneira de contar histórias com } \\
\text { livros infantis por parte dos } \\
\text { familiares participantes deste estudo. } \\
\text { Os efeitos produzidos } \\
\text { proporcionaram uma participação } \\
\text { mais produtiva no desenvolvimento } \\
\text { de linguagem das crianças. }\end{array}$ \\
\hline $\begin{array}{l}\text { DOS SANTOS, Sandra de } \\
\text { Lima Ribeiro; ALMEIDA- } \\
\text { VERDU, Ana Claudia } \\
\text { Moreira. 2012. Leitura em } \\
\text { uma criança surda após } \\
\text { equivalência de estímulos. }\end{array}$ & $\begin{array}{l}\text { Verificar os efeitos do ensino } \\
\text { sistemático da relação entre } \\
\text { palavras impressas e sinais da } \\
\text { Libras (Língua Brasileira de } \\
\text { Sinais) sobre a emergência de } \\
\text { leitura em um aluno com } \\
\text { surdez bilateral profunda, com } \\
9 \text { anos e } 4 \text { meses de idade, no } \\
4^{\circ} \text { ano do ensino fundamental. }\end{array}$ & $\begin{array}{l}\text { Esse procedimento foi efetivo para } \\
\text { que o participante emitisse sinais, } \\
\text { convencionados com a comunidade } \\
\text { verbal da Libras, diante de estímulos } \\
\text { textuais, o que caracteriza a leitura. }\end{array}$ \\
\hline $\begin{array}{l}\text { PINOTTI, Kele Jaqueline; } \\
\text { BOSCOLO, Cibele Cristina. } \\
\text { 2008. A dramatização como } \\
\text { estratégia de aprendizagem } \\
\text { da linguagem escrita para o } \\
\text { deficiente auditivo. }\end{array}$ & $\begin{array}{l}\text { Verificar a possibilidade da } \\
\text { arte de dramatizar ser um } \\
\text { instrumento terapêutico que } \\
\text { facilite o desenvolvimento da } \\
\text { interpretação e compreensão } \\
\text { de textos pelos deficientes } \\
\text { auditivos. }\end{array}$ & $\begin{array}{l}\text { Os participantes melhoraram a } \\
\text { compreensão em 100\%. Foram } \\
\text { capazes de se expressar mesmo com } \\
\text { dificuldades gramaticais e sintáticas. } \\
\text { A dramatização possibilitou ao surdo } \\
\text { experienciar o texto e compreender o } \\
\text { que não compreenderia apenas com a } \\
\text { leitura. }\end{array}$ \\
\hline $\begin{array}{l}\text { SCHEMBERG, Simone et } \\
\text { al. 2009. As práticas de } \\
\text { letramento na escola e na } \\
\text { família no contexto da } \\
\text { surdez: reflexões a partir do } \\
\text { discurso dos pais e } \\
\text { professores. }\end{array}$ & $\begin{array}{l}\text { Analisar e discutir as práticas } \\
\text { de letramento que permeiam } \\
\text { os meios familiar e escolar de } \\
\text { um grupo de crianças surdas. }\end{array}$ & $\begin{array}{l}\text { As práticas de leitura são restritas no } \\
\text { âmbito familiar, o que implica em } \\
\text { refletir sobre como se constituem } \\
\text { enquanto sujeito letrado. No espaço } \\
\text { escolar, as práticas de leitura e } \\
\text { escrita são constituídas a partir do } \\
\text { livro didático, o que revela a falta de } \\
\text { diversidade de gênero textual em } \\
\text { sala de aula. }\end{array}$ \\
\hline
\end{tabular}

(continua) 


\begin{tabular}{|c|c|c|}
\hline Autor/Ano/ Título & Objetivos & Conclusão \\
\hline $\begin{array}{l}\text { CHAVEIRO, Neuma et al. } \\
\text { 2013. Instrumentos em } \\
\text { Língua Brasileira de Sinais } \\
\text { para avaliação da qualidade } \\
\text { de vida da população surda. }\end{array}$ & $\begin{array}{l}\text { Construir a versão, em Língua } \\
\text { Brasileira de Sinais, dos } \\
\text { instrumentos } \text { WHOQOL- } \\
\text { BREF e WHOQOL-DIS para } \\
\text { avaliar a qualidade de vida da } \\
\text { população surda brasileira. }\end{array}$ & $\begin{array}{l}\text { Os instrumentos em Libras } \\
\text { possibilitarão que os surdos se } \\
\text { expressem autonomamente quanto a } \\
\text { sua qualidade de vida, o que } \\
\text { permitirá investigar com mais } \\
\text { precisão essas questões. }\end{array}$ \\
\hline $\begin{array}{l}\text { CARNIO, Maria Sílvia; } \\
\text { CSIPAI, Eleonora Silva; } \\
\text { COUTO, Maria Inês Vieira. } \\
\text { 2010. Relação entre níveis } \\
\text { de compreensão e } \\
\text { estratégias de leitura } \\
\text { utilizadas por surdos } \\
\text { sinalizadores em um } \\
\text { programa terapêutico. }\end{array}$ & $\begin{array}{l}\text { Determinar as mudanças } \\
\text { referentes às estratégias de } \\
\text { aprendizagem nos níveis de } \\
\text { compreensão de leitura durante } \\
\text { um programa de intervenção } \\
\text { fonoaudiológica direcionado } \\
\text { aos surdos sinalizadores. }\end{array}$ & $\begin{array}{l}\text { O programa propiciou que } \\
\text { estudantes surdos sinalizadores } \\
\text { utilizassem mais estratégias de } \\
\text { elaboração e menos de de } \\
\text { monitoramento, facilitando a } \\
\text { passagem do nível de decodificação } \\
\text { para o nível de compreensão literal } \\
\text { do texto. }\end{array}$ \\
\hline $\begin{array}{l}\text { ARAUJO, Claudia Campos } \\
\text { Machado; LACERDA, } \\
\text { Cristina Broglia Feitosa de. } \\
\text { 2008. Esferas de atividade } \\
\text { simbólica e a construção de } \\
\text { conhecimento pela criança } \\
\text { surda. }\end{array}$ & $\begin{array}{l}\text { Abordar e explorar as esferas } \\
\text { simbólicas da linguagem - } \\
\text { gesto, desenho, narrativa e } \\
\text { escrita - concomitante à língua } \\
\text { de sinais no desenvolvimento } \\
\text { de linguagem da criança surda } \\
\text { e na construção de novos } \\
\text { conhecimentos. }\end{array}$ & $\begin{array}{l}\text { As atividades simbólicas } \\
\text { favoreceram a ampliação da língua } \\
\text { de sinais e acessos iniciais à escrita, } \\
\text { abrindo espaço para a consolidação } \\
\text { de signos e para o desenvolvimento } \\
\text { de linguagem. O uso prioritário da } \\
\text { língua de sinais, além de considerar } \\
\text { as particularidades linguísticas e as } \\
\text { mediações semióticas, foi } \\
\text { fundamental para o desenvolvimento } \\
\text { da linguagem da criança surda e para } \\
\text { a construção de conhecimentos, de } \\
\text { maneira satisfatória e adequada à sua } \\
\text { constituição como sujeito ativo e } \\
\text { participante da linguagem. }\end{array}$ \\
\hline $\begin{array}{l}\text { CAPOVILLA, Fernando C. } \\
\text { 2008. Recursos para } \\
\text { educação de crianças com } \\
\text { necessidades especiais e } \\
\text { articulação entre educação } \\
\text { especial e inclusiva. }\end{array}$ & $\begin{array}{l}\text { Este breve artigo de revisão } \\
\text { sumaria alguns recursos } \\
\text { disponíveis para escolarização } \\
\text { e alfabetização de crianças } \\
\text { com dificuldade escolar, bem } \\
\text { como de crianças com } \\
\text { distúrbios de comunicação e } \\
\text { linguagem de etiologia } \\
\text { neurossensorial (e.g., surdez } \\
\text { congênita), neuromotora (e.g., } \\
\text { paralisia cerebral) e } \\
\text { neurolinguística (e.g., dislexia } \\
\text { do desenvolvimento). }\end{array}$ & $\begin{array}{l}\text { A articulação entre educação } \\
\text { especial e educação inclusiva, em } \\
\text { contraturno, funciona como base } \\
\text { para preparar a criança para aprender } \\
\text { e prosperar na escola comum. A } \\
\text { escola comum funciona como campo } \\
\text { de prova para assistir a educação } \\
\text { especial na descoberta e calibragem } \\
\text { de implementações capazes de tornar } \\
\text { a criança efetivamente apta a } \\
\text { aprender e prosperar na escola } \\
\text { comum, vicejando academicamente } \\
\text { e se integrando socialmente. }\end{array}$ \\
\hline
\end{tabular}

Fonte: Dados da pesquisa. 
Quadro 3. Estudos referentes à adaptação do ambiente pedagógico como facilitadores do processo de aprendizagem. Goiânia, 2018.

\begin{tabular}{|c|c|c|}
\hline Autor/Ano/ Título & Objetivos & Conclusão \\
\hline $\begin{array}{l}\text { GUARINELLO, Ana } \\
\text { Cristina et al. 2008. O } \\
\text { intérprete universitário } \\
\text { da Língua Brasileira de } \\
\text { Sinais na cidade de } \\
\text { Curitiba. }\end{array}$ & $\begin{array}{l}\text { Discutir e explicitar questões } \\
\text { relativas ao trabalho de } \\
\text { intérpretes de língua de sinais } \\
\text { em uma universidade e dois } \\
\text { centros universitários } \\
\text { particulares da cidade de } \\
\text { Curitiba. }\end{array}$ & $\begin{array}{l}\text { No cenário da educação dos surdos } \\
\text { brasileiros, essas questões apenas refletem } \\
\text { o descaso das autoridades com relação à } \\
\text { educação dessa população e evidenciam as } \\
\text { dificuldades linguísticas e sociais relativas } \\
\text { à surdez. }\end{array}$ \\
\hline $\begin{array}{l}\text { ASPILICUETA, } \\
\text { Patricia et al. } 2013 . \text { A } \\
\text { questão linguística na } \\
\text { inclusão escolar de } \\
\text { alunos surdos: } \\
\text { ambiente regular } \\
\text { inclusivo versus } \\
\text { ambiente } \\
\text { exclusivamente ouvinte. }\end{array}$ & 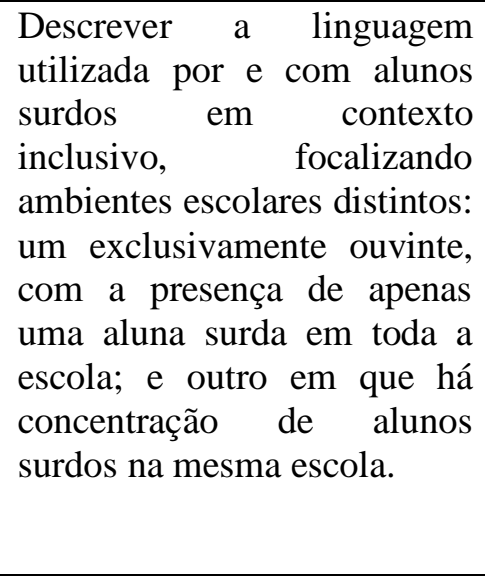 & $\begin{array}{l}\text { A presente pesquisa possibilitou } \\
\text { vislumbrarmos a centralidade da questão } \\
\text { linguística na educação de surdos. As } \\
\text { dificuldades apresentadas por alunos } \\
\text { surdos em compreender textos e sua escrita } \\
\text { permeada por construções singulares, que } \\
\text { atravessam as regras da língua portuguesa e } \\
\text { acarretam a perda de sentido do texto, } \\
\text { afetam todas as disciplinas escolares. } \\
\text { Some-se a isso o fato de que a linguagem é } \\
\text { constitutiva do sujeito e as questões } \\
\text { comunicativas e interacionais que ela } \\
\text { implica. }\end{array}$ \\
\hline $\begin{array}{l}\text { NUNES, Sylvia da } \\
\text { Silveira et al. } 2015 . \\
\text { Surdez e educação: } \\
\text { escolas inclusivas e/ou } \\
\text { bilíngues? }\end{array}$ & $\begin{array}{l}\text { Debater as questões que } \\
\text { envolvem a escolarização do } \\
\text { sujeito surdo, contribuindo } \\
\text { para as propostas sobre a sua } \\
\text { educação. }\end{array}$ & $\begin{array}{l}\text { Concluímos que políticas públicas que } \\
\text { valorizem a Língua Brasileira de Sinais } \\
\text { (Libras) tanto nos espaços escolares como } \\
\text { nos demais espaços sociais seriam um } \\
\text { caminho para que o aluno surdo não tivesse } \\
\text { acesso à Libras apenas na escola. }\end{array}$ \\
\hline $\begin{array}{l}\text { CRUZ, José Ildon } \\
\text { Gonçalves da; DIAS, } \\
\text { Tárcia Regina da } \\
\text { Silveira. } 2009 . \\
\text { Trajetória escolar do } \\
\text { surdo no ensino } \\
\text { superior: condições e } \\
\text { possibilidades. }\end{array}$ & $\begin{array}{l}\text { Conhecer as suas condições } \\
\text { nesse nível de ensino. }\end{array}$ & $\begin{array}{l}\text { Concluiu-se que os surdos são capazes, } \\
\text { produtivos, solidários e interessados em } \\
\text { avançar no seu processo de escolarização, } \\
\text { apesar dos empecilhos encontrados no } \\
\text { interior do espaço escolar. }\end{array}$ \\
\hline $\begin{array}{l}\text { GUARINELLO, Ana } \\
\text { Cristina et al. } 2009 . \\
\text { Surdez e letramento: } \\
\text { pesquisa com surdos } \\
\text { universitários de } \\
\text { Curitiba e } \\
\text { Florianópolis. }\end{array}$ & $\begin{array}{l}\text { Apresentar aspectos que } \\
\text { caracterizem as condições de } \\
\text { letramento de surdos } \\
\text { estudantes universitários, } \\
\text { investigando o desempenho } \\
\text { desses surdos em atividades } \\
\text { de leitura e de escrita. }\end{array}$ & $\begin{array}{l}\text { No contexto da surdez, ainda contamos } \\
\text { com leitores e escritores que apresentam } \\
\text { grande dificuldade no processo de } \\
\text { interpretação e produção textual de gêneros } \\
\text { secundários. Esse estudo aponta, assim, a } \\
\text { importância de um trabalho de letramento } \\
\text { desde a escola fundamental até a } \\
\text { universidade, que envolva práticas nos } \\
\text { mais diversos tipos de gêneros. }\end{array}$ \\
\hline
\end{tabular}

Fonte: Dados da pesquisa. 


\section{Discussão}

As pessoas surdas, assim como qualquer outro grupo social, se organizam por meio de características comuns, ou seja, pelos códigos culturais, linguísticos e valores que os identificam (KARNOPP et al., 2011). A percepção visual é de fundamental importância para essa população, já que é por meio dela que exploram o mundo que a cerca e estabelecem vínculos afetivos, sociais e comunicativos. Por isso, o contexto educacional torna-se imprescindível, porque possibilita o encontro surdo-surdo (PAULA, 2009; QUADROS, 2003).

A língua de sinais é considerada um sistema linguístico legítimo, que atende a todos os critérios de uma língua genuína no léxico, na sintaxe e na capacidade de gerar uma quantidade infinita de sentenças. Pode expressar qualquer conceito que advém da necessidade comunicativa do ser humano (GESSER, 2009).

Enquanto as línguas orais apresentam modalidade de produção oral auditiva, as línguas de sinais apresentam modalidade de produção visuoespacial, ou seja, as informações são recebidas pelos olhos e produzidas pelas mãos, acrescidas de expressões faciais e corporais. São constituídas por sinais, e não por palavras. Os sinais podem ser icônicos, que fazem alusão à imagem do seu significado, ou arbitrários, que não mantêm qualquer semelhança com o dado da realidade que representam (FRYDRYCH, 2012).

Os artigos que compõem o Quadro 1 - e discutem o impacto das diferenças linguísticas entre a Libras e o Português no processo de aprendizagem — sinalizam a importância da aquisição da Libras desde os anos iniciais e remetem às dificuldades de aprendizagem apresentadas pelos surdos à demora no diagnóstico da surdez, o que implica atraso na aquisição da sua língua. Afirmam que o contexto familiar oralizado a que são expostos impede o desenvolvimento adequado da linguagem (QUADROS, 2005).

Mesmo após o diagnóstico, é comum que a criança surda seja exposta apenas à linguagem oral. Esse fato, além de prejudicar o processo de significação e a aquisição de uma língua estruturada nos aspectos visuoespaciais no tempo correto, impede a criança surda de constituir-se leitora/escritora de uma língua que não domina (ARAUJO; LACERDA, 2008). A falta de conhecimentos linguísticos adquiridos a partir da interação com o meio e com o outro causa um déficit sintático e vocabular que dificulta o alcance de um bom nível de leitura, dificultando a interpretação da linguagem figurada (GAROLLA; CHIARI, 2003; PEREIRA, 2002). 
Embora o desenvolvimento cognitivo seja oportunizado pelos estímulos naturais do ambiente, o desenvolvimento da linguagem fica restrito pela dificuldade de compreender os contextos na ausência da audição e isso também os restringe no momento da aprendizagem dos conteúdos escolares apresentados apenas por meio da língua portuguesa oral e escrita. Fica claro, então, o importante papel que a Libras assume no processo de ensino e de aprendizagem da criança surda, já que ela é a língua capaz de lhe oferecer os recursos necessários à ampliação de significados e significantes (QUADROS, 2005).

O desenvolvimento precoce da língua de sinais está diretamente relacionado com o êxito escolar da criança surda e impacta diretamente na qualidade da escrita do português. No Brasil, embora as pesquisas que objetivam avaliar a competência linguística dos surdos usuários da Libras na escrita do português sejam restritas, estudos internacionais enfatizam que crianças surdas com acesso à língua de sinais desde os primeiros anos de vida têm mais facilidade no aprendizado da língua escrita (HERMANS et al., 2008).

Como a comunicação com ouvintes é dificultada pelo fato de não compartilharem uma mesma língua, a escrita assume um papel importante na inserção social do surdo. No entanto, o fato de utilizar a língua de sinais como primeira língua pode levá-lo a ter dificuldade para ler — tendo em vista que os textos são apresentados apenas na modalidade escrita da língua portuguesa - e escrever, visto a escassez do uso de categorias gramaticais, de verbos e de preposições em suas produções escritas (ANDRADE, 2007; CABRAL, 2005; QUADROS, 2005).

A Libras, assim como as demais línguas de sinais, tem gramática própria e diferente da estrutura gramatical que compõe a língua portuguesa. Até o final da década de 1990, os estudos realizados objetivaram compreender a escrita do surdo a partir da comparação da competência linguística de surdos e de ouvintes, evidenciando, assim, uma defasagem do surdo em relação ao ouvinte e ignorando o fato de que a surdez é uma condição que dificulta o desenvolvimento da escrita em função da falta de feedback auditivo. Já os estudos desenvolvidos na primeira década do século XXI buscaram compreender os processos de leitura e escrita do surdo não por suas dificuldades, mas pela funcionalidade da sua escrita, analisando os aspectos de coesão e coerência (ANDRADE, 2007; FERNANDES, 1990; SILVA, 2001).

Dentre as dificuldades apresentadas pelos surdos no processo da aquisição do português, especialmente da sua modalidade escrita, o domínio das flexões de tempo no 
processo de construção frasal consta como a maior delas. Um estudo realizado com 18 surdos, estudantes do $3^{\circ}$ ao $6^{\circ}$ ano do Ensino Fundamental, para comparar os marcadores de tempo utilizados na produção de frases em Libras e em português escrito, concluiu que os surdos utilizam adequadamente os marcadores de tempo nas frases elaboradas em Libras, mas apresentam dificuldade em marcar o tempo na língua portuguesa escrita. Esse desempenho melhora com o aumento do grau de escolaridade (CRATO; CARNIO, 2010).

Essas diferenças não devem ser tomadas como empecilho. Devem servir de referência pedagógica para o trabalho com a aquisição da escrita pelo surdo. Para isso, é fundamental apontar, aos professores que trabalham com os surdos, a interferência da Libras na aprendizagem do português escrito e ressaltar que a diferença das modalidades dessas duas línguas exige modos diferentes de conduzir o processo de ensino (QUINTANO-NEIRA; CÁRNIO, 2005).

As avaliações do rendimento acadêmico realizadas pelo Ministério da Educação têm revelado as dificuldades dos alunos surdos no processo de alfabetização. Apenas 5\% dos estudantes apresentam, ao final do $4^{\circ}$ ano do Ensino Fundamental, leitura com compreensão e uma escrita com características gramaticais pertinentes. Uma das barreiras apontadas para o fracasso no processo de alfabetização de pessoas surdas é a comunicação ineficaz, tanto aquela realizada pela oralidade como a feita pela língua de sinais (BRASIL, 2006).

Ao aprender a escrita de uma nova língua, o ouvinte busca na sua língua materna os conceitos para interpretar os novos conhecimentos. Assim também acontece com o surdo. Ao necessitar de subsídios para adquirir novos contextos e significações, ele busca na língua de sinais o apoio necessário para elaborar sua escrita. Essa interferência é percebida nas produções com ausência de conectivos entre palavras e frases, diferenças no uso de artigos, além da ausência de flexão de verbos e adjetivos, que são características estruturais da Língua de Sinais. Ou seja, as diferenças linguísticas entre a Libras e o Português impactam de forma significativa no processo de escolarização do surdo (PEIXOTO, 2006).

Os artigos que compõem o Quadro 2, que discutem a importância do uso de metodologias e estratégias pedagógicas adaptadas para o processo de aprendizagem do surdo, destacam o papel importante da linguagem no desenvolvimento humano, visto que ela organiza pensamentos e sentimentos, categoriza conceitos e significados, permitindo a socialização e aquisição de novos conhecimentos. Nesse contexto, a interação torna-se 
essencial, pois é dessa forma que a criança tem acesso à palavra e se apropria de seu conceito em um processo dinâmico (ARAUJO; LACERDA, 2008).

Ressaltam que, no contexto escolar, uma grande barreira enfrentada pelo surdo no processo de aquisição da leitura e da escrita é a ausência de uma língua comum na sala de aula, que o impede de atuar de forma efetiva nos contextos linguísticos. Enquanto a criança ouvinte apoia-se nos conhecimentos já adquiridos da linguagem oral para o desenvolvimento da linguagem escrita, a criança surda, que não chega à escola com conceitos suficiente para atribuir sentido à escrita, tem seu acesso à escrita cerceado (BOTELHO, 2002). Portanto, é necessário o uso de estratégias pedagógicas adaptadas no processo de aprendizagem do surdo, uma vez que as práticas de leitura e escrita desenvolvidas em sala de aula privilegiam aspectos que partem da linguagem oral (PEIXOTO, 2006).

A leitura e a compreensão plena de um texto requerem diferentes processos cognitivos, como memória, inferência, identificação de palavras, de letras e certo vocabulário já construído. Para compreender um texto em sua completude, os surdos sinalizadores amparam-se nas imagens existentes, usam a datilologia e fazem apoio articulatório e de gestos durante a leitura. Portanto, sendo a compreensão beneficiada pelo uso de estratégias diferenciadas, quanto mais possibilidades o estudante surdo sinalizador tiver, melhor será seu nível de leitura e compreensão (CÁRNIO et al., 2010).

Ao comparar o desenvolvimento cognitivo e linguístico de 7.500 crianças surdas e deficientes auditivas, estudantes do ensino fundamental de escolas públicas e privadas de 15 estados brasileiros, identificou-se que os estudantes surdos cuja língua materna é a Libras apresentam um desempenho melhor quando inseridos em escolas especificas para surdos, com professores que ministram ensino em Libras. Já os alunos com deficiência auditiva, que têm como língua materna o português, apresentam melhor rendimento sob regime de inclusão em escolas regulares, com professores que promovem aulas em português. Esse achado sinaliza a importância de articular as educações inclusiva e especial para superar a descontinuidade entre Libras e português (CAPOVILLA; CAPOVILLA, 2004).

O não reconhecimento da língua de sinais como a língua do surdo, o uso de livros didáticos, a ausência de práticas discursivas com o aluno surdo, a utilização da mesma metodologia em sala de aula para alunos ouvintes e surdos, a linguagem escrita geralmente ensinada em circunstâncias descontextualizadas e artificiais são dificuldades apresentadas 
como interferência no processo de aprendizagem do surdo, tanto no ambiente escolar quanto no contexto familiar (SCHEMBERG et al., 2009).

No contexto familiar é necessário que os pais compreendam a importância do seu papel como facilitadores da construção e do desenvolvimento do processo de linguagem de seus filhos, de maneira a proporcionar um ambiente que amplie os conhecimentos linguísticos e favoreça o desenvolvimento da linguagem. Portanto, é fundamental que a intervenção fonoaudiológica abarque orientações à família, dando importância ao uso de livros para contar histórias, oferecendo papel e lápis, ou seja, precisam compor o ambiente da casa com elementos que possam introduzir o universo da escrita (NASCIMENTO; KESSLER, 2015).

Além da família, os profissionais da educação também precisam ser qualificados para atuarem com a criança surda no contexto da sala de aula, já que a utilização de estratégias pedagógicas adaptadas é fundamental para uma melhor integração social e otimização da comunicação (GUARINELLO; LACERDA, 2007). Além disso, a apresentação da escrita de forma artificial e descontextualizada coloca em risco o processo de escolarização do surdo. A falta de ordenação dos vocábulos, do uso adequado da sintaxe nas frases, assim como a pequena quantidade de elementos de ligação, flexões e concordâncias, são aspectos apontados como consequência dessa interferência equivocada (PINOTTI; BOSCOLO, 2008).

Com o objetivo de verificar a contribuição da dramatização na interpretação e compreensão de textos foi realizado uma pesquisa com quatro deficientes auditivos, com idade entre 9 e 15 anos. Os resultados evidenciaram que esse recurso é muito eficaz e deve ser utilizado como estratégia de aprendizagem nas escolas, visto que os participantes melhoraram em $100 \%$ a compreensão dos textos e foram capazes de expressar, ainda que com distorções gramaticais e sintáticas, o conteúdo apresentado (PINOTTI; BOSCOLO, 2008).

Enfim, diante do cenário apresentado pelos artigos que compõem esse quadro, há de se considerar a qualidade de vida do surdo. Para tanto, é necessário compreender que a Libras não somente é um sistema linguístico, mas também um elemento fundamental para a constituição da identidade e da cultura do sujeito surdo. $\mathrm{O}$ acesso a ela permite que o surdo trace a representação de si próprio e do mundo (CHAVEIRO et al., 2013).

Os artigos que compõem o Quadro 3 discutem a importância da adaptação do ambiente pedagógico como facilitador do processo de aprendizagem do surdo, destacando a importância do uso da Libras e a carência de intérpretes em sala de aula como dificuldades para a efetivação da sua inclusão, ainda que já haja leis que favoreçam esse processo. 
Dentre as implicações que a surdez acarreta, a linguagem é considerada um fator marcante, uma vez que o surdo necessita de recursos adaptados para compensar a perda auditiva. Sendo a língua de sinais naturalmente a primeira língua do surdo e a língua oral majoritária sua segunda língua, é mister questionar como a inclusão do surdo tem sido feita na escola regular em que a língua utilizada, tanto para o ensino quanto para a socialização, é o português em suas modalidades oral e escrita (ASPILICUETA et al., 2013).

Os entraves para exercerem o direito à comunicação em Libras podem ser constatados no acesso à educação, cultura, lazer, informação, etc., porém, é na escola que essas barreiras se concretizam de forma mais excludente, pois, ademais das barreiras de comunicação, há a imposição para que o surdo se enquadre nos padrões do ouvinte. Nesse sentido, torna-se um equívoco compreender a educação inclusiva a partir da comparação com os ouvintes, desconsiderando as diferenças sócio-histórico-culturais e linguística dos surdos (NUNES et al., 2015).

As principais dificuldades enfrentadas para a inclusão escolar dos alunos surdos estão relacionadas aos professores e aos próprios surdos. Aos professores, por não disporem de conhecimento acerca da surdez e da Libras, e aos surdos, pela dificuldade de compreensão do contexto que os envolvem. Desse modo, a inclusão da Libras nas escolas e nos currículos dos cursos de Licenciatura é de fundamental importância, visto que oportuniza a comunicação efetiva dessa população entre si e com o outro (NUNES et al., 2015; PAULA, 2009).

Um estudo comparativo foi realizado para descrever a linguagem utilizada por e com alunos surdos em ambientes escolares distintos - um exclusivamente ouvinte, com a presença de apenas uma aluna surda; e outro em que há concentração de alunos surdos na mesma escola — , tendo revelado que a escola em que há presença de vários surdos e investe na formação dos professores em Libras e metodologias diferenciadas promove a inclusão. Em contrapartida, na escola em que não há a presença de mais alunos surdos e segue o modelo oralista, a única aluna surda matriculada não fez uso da língua de sinais e nem de linguagem oral de modo significativo (ASPILICUETA et al., 2013).

Vale reforçar que a interação da criança surda com outros surdos sinalizadores é fundamental para se tornarem fluentes em Libras, como ocorre com as crianças ouvintes que interagem com falantes de sua língua desde o nascimento. Nessa perspectiva, considera-se que a escola de surdos, do ponto de vista linguístico, seria satisfatória para a criança surda em fase de aquisição de Libras como primeira língua, uma vez que, na escola de surdos, a criança 
surda poderá apropriar-se da Libras, tornando-se falante dessa língua, o que será essencial para qualquer aprendizagem no âmbito acadêmico e social, bem como para sua constituição como sujeito (ASPILICUETA et al., 2013; SÁ, 2011).

No que se refere à presença de intérpretes, a maioria das escolas brasileiras encontramse no mesmo contexto, pois ainda são escassas as que têm promovido a inserção do intérprete em sala de aula como possibilidade para resolver ou amenizar problemas linguísticos dessa população no ambiente escolar (ASPILICUETA et al., 2013).

Embora o Decreto ${ }^{\circ}$ 5.626/2005 tenha legitimado o intérprete da língua de sinais, a formação desse profissional deve efetivar-se por meio de curso superior de Tradução e Interpretação, com habilitação em Libras/Língua Portuguesa, o que permite a sua atuação na Educação Infantil, na Educação Fundamental e também no Ensino Superior (GUARINELLO et al., 2008).

A inserção do intérprete da Libras na escola permite que o aluno surdo receba o conteúdo na sua língua, respeita sua condição linguística e amplia a chance de construir novos conhecimentos (LACERDA, 2000), no entanto, apenas a presença do intérprete não é suficiente para a inclusão do surdo. É preciso, também, criar um projeto educacional complexo, que assuma a surdez com suas características próprias, revisando as estratégias pedagógicas, atentando-se também para a organização do espaço acadêmico e dispondo de um currículo que favoreça as necessidades da comunidade surda (ASPILICUETA et al., 2013; GUARINELLO et al., 2008).

A valorização da Libras, capacitação dos professores, fazer uso de adaptações voltadas para as estratégias de ensino e para o material didático, a realização de formação continuada, inclusive com a presença de profissionais como fonoaudiólogos para discutir questões gerais e específicas da linguagem e a necessidade educacional do surdo são ações que favorecem a inclusão e a permanência do aluno surdo na escola (ASPILICUETA et al., 2013).

Esse contexto discutido nos artigos apresentados evidencia que, para se ter um ambiente pedagógico facilitador da aprendizagem do surdo, são necessárias várias adaptações, desde o ambiente físico até a capacitação de recursos humanos. A atual condição de acesso do aluno surdo à educação revela o descaso das autoridades com relação à educação desses sujeitos, expondo as dificuldades linguísticas e sociais referentes à surdez. 


\section{Conclusão}

Apesar de os surdos terem um amparo legal através da Lei $n^{\circ} 10.436 / 02$, de 24 de abril de 2002, que reconhece a Libras como meio oficial de comunicação e expressão da comunidade surda, e do Decreto $\mathrm{n}^{\mathrm{o}} 5.626 / 05$ que garante o atendimento às necessidades educacionais especiais de alunos surdos, como recursos didáticos que apoiem a educação destes alunos, observa-se que nas instituições de educação o ambiente pedagógico ignora as necessidades do surdo e seu direito adquirido.

Nos achados da literatura revisada, conclui-se que a principal barreira enfrentada pelo surdo usuário de Libras no seu processo de escolarização centra-se na ausência de uma comunicação eficaz com os ouvintes e com outros surdos, já que muitos chegam à escola sem o conhecimento dessa língua. Um dos fatores primordiais para a inclusão do surdo é ofertar o acesso à Libras para o próprio surdo, professores, funcionários e familiares. Além disso, sinaliza o impacto significativo causado pelas diferenças linguísticas existentes entre a Libras e o português oral e escrito, as quais dificultam a compreensão completa de textos e propiciam uma produção escrita marcada pela ausência de conjugação verbal, uso de artigos e preposições.

Ao conhecer a forma pela qual o surdo adquire conhecimento, pode-se estabelecer recursos e estratégias que venham a contribuir com um processo de escolarização com qualidade, tais como: atividades que contemplem a modalidade visuoespacial, a promoção de capacitação de toda a comunidade educativa em Libras, a presença do fonoaudiólogo para realizar orientação aos professores e familiares quanto ao que é surdez, suas implicações e como os surdos se apropriam da linguagem. A presença do intérprete na escola é outro fator importante para a inclusão escolar do surdo, visto que amplia a chance de ele desenvolver-se e construir novos conhecimentos, pois receberá o conteúdo escolar em sua língua.

Não podemos deixar de citar o papel fundamental da família no desenvolvimento da linguagem da criança surda. A falta de orientação e conhecimento a respeito do modo como o surdo adquire a linguagem impede ou retarda esse processo. Portanto, é fundamental que a intervenção fonoaudiológica abarque orientações à família, para que ela proporcione um ambiente capaz de ampliar os conhecimentos linguísticos e favorecer o desenvolvimento da linguagem do surdo. 


\begin{abstract}
Inclusive education policy aims at inclusive education. Although the legislation recognizes Libras as the official language of the deaf, this population has difficulties in the schooling process. Thus, this study aims to investigate the main barriers faced by the deaf in the schooling process through a review of the literature, conducted in the Virtual Health Library (VHL) in September 2018. We identified 19 publications, categorized in tables divided by author(s), year, title, objective and conclusion. The absence of effective communication and linguistic differences between Libras and Portuguese, as well as the lack of adaptation of pedagogical activities and knowledge of the impacts of deafness in the process of acquiring writing, are pointed as barriers to their schooling process. The presence of the interpreter thus becomes important for the school inclusion of the deaf.
\end{abstract}

Keywords: deafness and learning, deafness and reading, deafness and writing, deafness and schooling.

\title{
Referências
}

ALMEIDA, E. O. C. et al. Coesão textual na escrita de um grupo de adultos surdos usuários da língua de sinais Brasileira. Revista CEFAC, v. 12, n. 2, p. 216-222, abr. 2010. Disponível em: http://www.scielo.br/scielo.php?script=sci_arttext\&pid=S1516-18462010000200007 \&lng=en\&nrm=iso. Acesso em: 2 dez. 2018.

ALMEIDA, K.; SANTOS, T. M. M. Seleção e adaptação de próteses auditivas em crianças. In: ALMEIDA, K.; IORIO, M. C. M. Próteses auditivas: fundamentos teóricos e aplicações clínicas. São Paulo: Lovise, 2003. p. 335-53.

ANDRADE, W. T. L. A relação entre oralidade e escrita em língua portuguesa no surdo. 2007. Dissertação (Mestrado) - Universidade Católica de Pernambuco, João Pessoa, 2007.

ANDRADE, W. T. L. et al. Sobre a coesão do texto dos surdos aos olhos dos ouvintes: o uso das marcas de oralidade na escrita. Interação em Psicologia, v. 14, n. 1, p. 13-20, 2010. Disponível em: https://revistas.ufpr.br/psicologia/article/view/12580.

ARAUJO, C. C. M.; LACERDA, C. B. F. Esferas de atividade simbólica e a construção de conhecimento pela criança surda. Revista Brasileira de Educação Especial, v. 14, n. 3, p. 427446, dez. 2008. Disponível em: http://www.scielo.br/scielo.php?script=sciarttext\&pid=S1413$65382008000300007 \& \operatorname{lng}=$ en $\& n r m=$ iso. Acesso em: $1^{\circ}$ dez. 2018.

ASPILICUETA, P. et al. A questão linguística na inclusão escolar de alunos surdos: ambiente regular inclusivo versus ambiente exclusivamente ouvinte. Revista Brasileira de Educação Especial, v. 19, n. 3, p. 395-410, set. 2013. Disponível em: http://www.scielo. br/scielo.php?script=sci_arttext\&pid=S1413-65382013000300007\&lng=en\&nrm=iso. Acesso em: 2 dez. 2018. 
BEHARES, L. Propuesta para la implantación en la educación bilingüe en el sordo. Uruguay: Consejo Nacional de Educación/Consejo de Educación Primaria, 1993.

BOTELHO, P. Linguagem e letramento na educação dos surdos - ideologias e práticas pedagógicas. Belo Horizonte: Autêntica, 2002.

BRASIL. Decreto Lei no 5626/2005, de 22 de dezembro de 2005. Diário Oficial da União, Brasília, 2005.

BRASIL. Secretaria de Direitos Humanos da Presidência da República. Secretaria Nacional de Promoção dos Direitos da Pessoa com Deficiência. Coordenação Geral do Sistema de Informações sobre a Pessoa com Deficiência. Cartilha do Censo 2010 - Pessoas com Deficiência. $2012 . \quad$ Disponível em: http://www.pessoacomdeficiencia.gov.br/app/sites/default/files/publicacoes/cartilha-censo2010-pessoas-com-deficienciareduzido.pdf.

BRASIL. Ministério da Educação e Cultura. Orientações para Implementação da Política de Educação Especial na Perspectiva da Educação Inclusiva. Brasil: MEC, 2015. Disponível em: http://portal.mec.gov.br/index.php?option=com_docman\&view=download\&alias=17237secadi-documento-subsidiario-2015\&Itemid=30192.

BRASIL. Ministério da Educação e Cultura. Secretaria de Educação especial. Coordenação Geral de Planejamento. Números da Educação Especial no Brasil. 2006. Disponível em: http://portal.mec.gov.br/seesp/. Acesso em: 10 maio. 2006.

BRASIL. Presidência da República. Casa Civil. Subchefia para Assuntos Jurídicos. Lei $n^{o}$ 9.394, de, 20 de dezembro de 1996. Estabelece as diretrizes e bases da educação nacional. Disponível em: http://www.planalto.gov.br/ccivil_03/LEIS/19394.htm.

BUFFA, M. J. M. B. O que os pais de crianças deficientes auditivas devem saber sobre a escola. In: BEVILACQUA, M. C.; MORET, A. L. M. (Eds.). Deficiência auditiva: conversando com familiares e profissionais de saúde. São José dos Campos: Pulso, 2005. p.295-306.

CABRAL, G. Perspectivas para uma pedagogia bilíngue: a educação infantil e o ensino fundamental no centro SUVAG de Pernambuco. In: CENTRO SUVAG DE PERNAMBUCO (Org.). Estudos surdos: novas perspectivas. Recife: Centro SUVAG de Pernambuco, 2005. p. 15-27.

CAPOVILLA, F. C. Recursos para educação de crianças com necessidades especiais e articulação entre educação especial e inclusiva. O Mundo da Saúde, v. 32, n. 2, p. 208-214, 2008.

CAPOVILlA, A. G. S.; CAPOVILlA, F. C. Problemas de leitura e escrita: como identificar, prevenir e remediar, numa abordagem fonológica. 4. ed. São Paulo: Memnon, 2004. 
CÁRNIO, M. S. et al. Relação entre níveis de compreensão e estratégias de leitura utilizadas por surdos sinalizadores em um programa terapêutico. Revista da Sociedade Brasileira de Fonoaudiologia, São Paulo, v. 15, n. 2, p. 206-212, 2010. Disponível em: http://www.scielo.br/scielo.php?script=sci_arttext\&pid=S1516-

80342010000200010\&lng=en\&nrm=iso. Acesso em: 2 dez. 2018.

CHAVEIRO, N. et al. Instrumentos em Língua Brasileira de Sinais para avaliação da qualidade de vida da população surda. Revista de Saúde Pública, v. 47, n. 3, p. 616-623, jun. 2013. Disponível em: https://scielosp.org/scielo.php?script=sci_arttext\&pid=S003489102013000500616.

CRATO, A. N.; CARNIO, M. S. Marcação de tempo por surdos sinalizadores brasileiros. Pró-Fono Revista de Atualização Científica, v. 22, n. 3, p. 163-168, set. 2010. Disponível em: http://www.scielo.br/scielo.php?script=sci_arttext\&pid=S0104-

$56872010000300002 \& \operatorname{lng}=$ en\&nrm=iso. Acesso em: $1^{\circ} \mathrm{dez} .2018$.

CRUZ, J. I. G.; DIAS, T. R. S. Trajetória escolar do surdo no ensino superior: condições e possibilidades. Revista Brasileira de Educação Especial, v. 15, n. 1, p. 65-80, abr. 2009. Disponível em: http://www.scielo.br/scielo.php?script=sci_arttext\&pid=S141365382009000100006\&lng=en\&nrm=iso. Acesso em: 2 dez. 2018.

DAVIS, H.; SILVERMANN, R. S. Hearing and deafness. New York: Holt, 1970.

FERREIRA, L. P. Tratado de fonoaudiologia. São Paulo: Roca, 2004.

FERNANDES, E. Problemas linguísticos e cognitivos dos surdos. Rio de Janeiro: Agir, 1990.

FRYDRYCH, L. A. K. Rediscutindo as noções de arbitrariedade e iconicidade: implicações para o estatuto linguístico da Língua de Sinais. ReVEL, v. 10, n. 19, p. 281-294, 2012.

GAROLLA, L. P.; CHIARI, B. M. Protocolo para avaliação da compreensão de leitura em crianças deficientes auditivas. Pró-Fono: Revista de Atualização Científica, v. 15, n. 3, p. 325-334, 2003.

GESSER, A. LIBRAS? Que língua é essa? Crenças e preconceitos em torno da língua de sinais e da realidade surda. São Paulo: Parábola, 2009.

GUARINELLO, A. C. et al. O intérprete universitário da Língua Brasileira de Sinais na cidade de Curitiba. Revista Brasileira de Educação Especial, v. 14, n. 1, p. 63-74, abr. 2008. Disponível em: http://www.scielo.br/scielo.php?script=sci_arttext\&pid=S141365382008000100006\&lng=en\&nrm=iso. Acesso em: 2 dez. 2018.

GUARINELLO, A. C.et al. Surdez e letramento: pesquisa com surdos universitários de Curitiba e Florianópolis. Revista Brasileira de Educação Especial, v. 15, n. 1, p. 99-120, abr. 2009. Disponível em: http://www.scielo.br/scielo.php?script=sci_arttext\&pid=S141365382009000100008\&lng=en\&nrm=iso. Acesso em: 2 dez. 2018. 
GUARINELLO, A. C.; LACERDA, C. B. F. O grupo de familiares de surdos como espaço de reflexão e de possibilidades de mudança. In: SANTANA, A. P. et al. Abordagens grupais em Fonoaudiologia: contextos e aplicações. 1. ed. São Paulo: Plexus, 2007. p.105-20.

HERMANS, D. et al. Modeling reading vocabulary learning in deaf children in bilingual education programs. Journal of Deaf Studies and Deaf Education, v. 13, n. 2, p. 155-174, 2008.

KARNOPP, L. B. et al. Cultura surda na contemporaneidade: negociações, intercorrências e provocações. Canoas: Editora da ULBRA, 2011.

LACERDA, C. B. F. A criança surda e a língua de sinais no contexto de uma sala de aula de alunos ouvintes. Relatório Final FAPESP Proc. No 98/02861-1, 2000.

MENDES, K. D. S. et al. Revisão integrativa: método de pesquisa para a incorporação de evidências na saúde e na enfermagem. Texto \& Contexto Enfermagem, v. 17, n. 4, p. 758-765, out.-dez. 2008.

NADER, J. M. V. A relação da língua materna com o ensino/aprendizagem de crianças surdas. In: SECRETARIA DE ESTADO DA SAÚDE, Rede de Informação e Conhecimento. Programa de Aprimoramento Profissional - PAP 2008. São Paulo: BR91.2/WA20/ CDRPAP02, 2008.

NASCIMENTO, G. B.; KESSLER, T. M. Efeitos de oficinas de contar histórias com livros infantis realizadas com familiares de crianças surdas. Revista CEFAC, v. 17, n. 4, p. 11031114, ago. 2015. Disponível em: http://www.scielo.br/scielo.php?script=sci_arttext\&pid=S151618462015000401103\&lng=en\&nrm=iso. Acesso em: 2 dez. 2018.

NUNES, S. S. et al. Surdez e educação: escolas inclusivas e/ou bilíngues? Psicologia Escolar e Educacional, v. 19, n. 3, p. 537-545, dez. 2015. Disponível em: http://www.scielo.br/scielo.php?script=sci_arttext\&pid=S1413-

85572015000300537\&lng=en\&nrm=iso. Acesso em: $1^{\circ} \mathrm{dez} .2018$.

PAULA, L. S. B. de. Cultura escolar, cultura surda e construção de identidades na escola. Revista Brasileira de Educação Especial, v. 15, n. 3, p. 407-416, 2009.

PEIXOTO, R. C. Algumas considerações sobre a interface entre a língua brasileira de sinais (LIBRAS) e a língua portuguesa na construção inicial da escrita pela criança surda. Caderno Cedes, v. 26, n. 69, p. 205-229, 2006.

PEREIRA, M. C. Discutindo o uso da sintaxe por estudantes surdos. In: BERBERIAN, A. P. et al. Linguagem escrita: referenciais para a clínica fonoaudiológica. São Paulo: Plexus, 2002. p. 111-124.

PEREIRA, V. A.; ALMEIDA-VERDU, A. C. M. Avaliação do ler e do escrever de surdos pela língua brasileira de sinais. Psicologia: teoria e prática, v. 14, n. 2, p. 15-27, ago. 2012. 
Disponível em: http://pepsic.bvsalud.org/scielo.php?script=sci_arttext\&pid=S151636872012000200002\&lng=pt\&nrm=iso. Acesso em: 2 dez. 2018.

PEREIRA, M. C. C.; VIEIRA, M. I. S. Bilinguismo e educação de surdos. Revista Intercâmbio, v. 19, p. 62-67, 2009.

PINOTTI, K. J.; BOSCOLO, C. C. A dramatização como estratégia de aprendizagem da linguagem escrita para o deficiente auditivo. Revista Brasileira de Educação Especial, v. 14, n. 1, p. 121-140, abr. 2008. Disponível em: http://www.scielo.br/scielo.php?script=sci_arttext\&pid=S141365382008000100010\&lng=en\&nrm=iso. Acesso em: 2 dez. 2018.

QUADROS, R. M. O 'BI' em bilingüismo na educação de surdos. In: FERNANDES, E. Surdez e bilingüismo. Porto Alegre: Mediação, 2005. p.26-36.

QUADROS, R. M. de. Situando as diferenças implicadas na educação de surdos: inclusão/exclusão. Ponto de Vista, n. 5, p. 81-111, 2003.

QUINTANO-NEIRA, P. R. N.; CÁRNIO, M. S. Caderno ilustrado de verbos: um recurso pedagógico para o desenvolvimento da Língua portuguesa. Barueri, SP: Pró-Fono, 2005.

SÁ, N. R. L. Surdos: qual escola? Manaus: Editora Valer e Edua, 2011.

SANTOS, S. L. R.; ALMEIDA-VERDU, A. C. M. Leitura em uma criança surda após equivalência de estímulos. Psicologia em Revista, v. 18, n. 2, p. 209-226, ago. 2012. Disponível em: http://pepsic.bvsalud.org/scielo.php?script=sci_arttext\&pid=S1677$11682012000200004 \& \operatorname{lng}=$ pt\&nrm=iso. Acesso em: 2 dez. 2018.

SCHEMBERG, S. et al. O. As práticas de letramento na escola e na família no contexto da surdez: reflexões a partir do discurso dos pais e professores. Revista Brasileira de Educação Especial, v. 15, n. 2, p. 251-268, ago. 2009. Disponível em: http://www.scielo.br/scielo.php?script=sci_arttext\&pid=S141365382009000200006\&lng=en\&nrm=iso. Acesso em: 2 dez. 2018.

SILVA, M. P. M. A construção de sentidos na escrita do aluno surdo. São Paulo: Plexus, 2001.

WELTER, G. et al. Intervenções e metodologias empregadas no ensino da escrita e leitura de indivíduos surdos: revisão de literatura. Revista Brasileira de Educação Especial, v. 21, n. 3, p. 459-470, set. 2015. Disponível em: http://www.scielo.br/scielo.php?script=sci_ arttext\&pid=S1413-65382015000300459\&lng=en\&nrm=iso. Acesso em: 2 dez. 2018. 